\title{
MATERIAL MODELING OF TEXTILE REINFORCED COMPOSITES WITH RESPECT TO FRACTURE INITIATION AND STRAIN RATE SENSITIVITY
}

\author{
$\underline{\text { M. Richter }}{ }^{1,2^{*}}$, H. Dell ${ }^{1}$, G. Oberhofer ${ }^{1}$, H. Gese ${ }^{1}$, F.Duddeck ${ }^{2}$ \\ ${ }^{1}$ MATFEM Partnerschaft Dr. Gese \& Oberhofer, Munich, Germany \\ ${ }^{2}$ School of Engineering and Design, Technical University of Munich, Germany \\ *Corresponding author: michael.richter@matfem.de
}

Textile reinforced composites exhibit promising material properties such as high strength and elevated capacity to absorb energy. Additionally, they can be deep drawn in a similar manner as conventional steel sheets and welded. Therefore, a thermo-forming can be combined with a back injection in the same mold, which allows to cast on functional parts. Hence, semi-finished products with woven textile structures show a promising potential for the substitution of $\mathrm{Al}$ or $\mathrm{Mg}$ in structural parts conventionally manufactured with ductile steel sheets. Endless glassfibers are woven into a weaving structure such as plain, twill or satin weave (See Figure 1) and embedded into a ductile thermoplastic matrix. The combination of a brittle fiber with high strength and a ductile matrix results in a complex material behavior of the composite. Therefore, reliable and comprehensive material models are needed for the simulation of structural loadcases. Industrial requirements on computational costs for the simulation of components necessitate a phenomenological approach while respecting the constitutive particularities of the two composite constituent's, fiber and matrix. In the modular material model MF GenYld+CrachFEM, the effective material behavior can be modeled on a macroscopic scale e.g. non-linear permanent deformations are captured in a smeared description.

Based on a comprehensive experimental program and a pre-conditioning to account for the moisture-dependent material behavior of a thermoplastic matrix, different modeling techniques will be presented and discussed for the organic sheet Tepex ${ }^{\circledR}$ dynalite 102RG600. For the simulation of crashworthiness and misuse load-cases the strain rate sensitivity and fracture need to be covered. Especially the influence of the strain rate sensitivity on the plastic hardening behavior and fracture of the fiber and matrix is differently pronounced and needs to be accounted for. Taking into account the heterogeneous micro-structure of the composite, failure initiation will be described with a strain-based and a stress-based failure envelope for the ductile matrix-dominated and brittle fiber-dominated in-plane directions respectively.
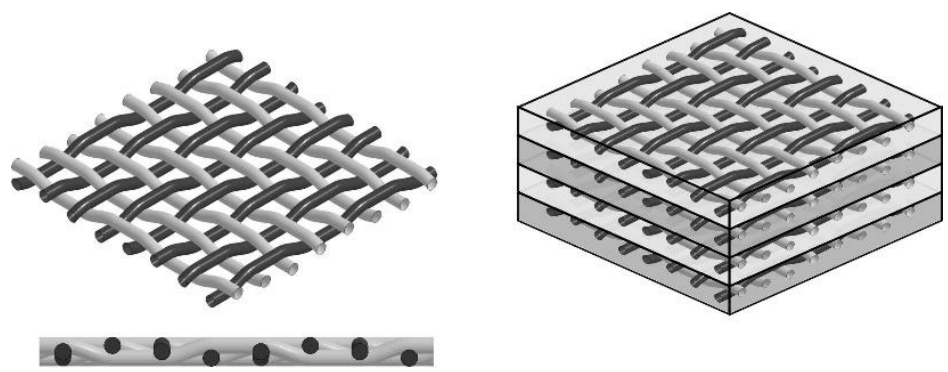

Figure 1. Isogeometric and side view of the bidirectional twill-weave architecture (left) and an example of a layered composite made from twill-weave layers (right) 